\title{
The Effects of Weibull Distribution on Supplier Comparison using Lower Process Capability Index: A Case Study
}

\author{
Erawin Thavorn ${ }^{1, *}$ and Prapaisri Sudasna-Na-Ayudthya ${ }^{2}$ \\ ${ }^{I}$ Department of Industrial Engineering, School of Engineering, University of Phayao, \\ Phayao 56000, Thailand \\ ${ }^{2}$ Department of Industrial Engineering, Faculty of Engineering, Kasetsart University, \\ Bangkok 10900, Thailand
}

('Corresponding author's e-mail: erawin.th@up.ac.th)

Received: 22 September 2020, Revised: 21 May 2021, Accepted: 31 May 2021

\begin{abstract}
In supplier comparison, durability, one of the quality dimensions, is important criterion. Lifetime data is widely used to measure the durability and commonly modeled with Weibull distribution. Many researchers employ process capability indices (PCIs) for comparing suppliers about quality aspect. However, applying these methods bring to some misleading results when lifetime data are considered because the methods are developed under normal distribution. This study attempts to develop the new method for comparing supplier using lower process capability index $\left(C_{p l}\right)$ to apply with the lifetime data. To be guideline for developing the new method, this research aims to study the effects of Weibull distribution on supplier comparison using $C_{p l}$ via a case study. The effect is studied through 2 performance measures, e.g., producer's risk and the power of test obtained by Monte Carlo simulation. The simulation results for Weibull distribution indicate that the process's shape influences on the performance measures obviously. For right-skewed process, the producer's risks are lower than $\alpha=0.05$, and power of tests do not exceed 0.10. Although power of tests are close to 1.00 in case of left-skewed process, the risks are greater than $\alpha=0.05$. For symmetric process, the producer's risks are close to $\alpha=$ 0.05 , but the power of tests do not exceed 0.40 in all cases. So, this study points out that the process's shape is an important factor affecting to the performance of supplier comparison using $C_{p l}$ leading to the possibly misleading results. To better understand the effects, this paper presents the example of supplier comparison using real data. The example shows that although the popular methods for handling Weibull distribution are applied, the supplier comparison results are not the same. So, manufacturers should be aware in supplier comparison regarding to lifetime data.
\end{abstract}

Keywords: Supplier comparison, Process capability indices, $C_{p l}$ index, Lifetime, Weibull distribution

\section{Introduction}

Nowadays, many manufacturers focus on outsourcing service to be the flexible business. As a result, they rely on many suppliers to achieve their goal. So, the manufacturers should emphasize on supplier comparison to select an appropriate supplier into their firms because it can add product value and enhance competitiveness to manufacturers [1]. There are many criteria for supplier comparison such as delivery, quality, quality history, production capacity, prices etc. Quality is the main criterion in comparing suppliers [2]. Abdolsha [2] reviews many supplier comparison methods about quality criterion such as rate of rejects and yield rate, integrating another criterion to supplier selection, Taguchi loss function and PCIs and indicates that PCIs are suitable tool for assessing the quality because they can assess the quality from product directly.

The PCIs are used to measure process capability of supplier or manufacturers regarding to specifications. The PCIs are divided into 2 types depended on specification limit, e.g., 1-sided and 2-sided PCIs. One-sided PCIs are commonly used in many industries because they are employed to consider the quality characteristics of "the larger is the better" or "the smaller is the better".

Several researchers apply the 1-sided PCIs based on normal distribution to compare suppliers with single quality characteristics. Chou [3] proposes the likelihood ratio method for 2-supplier comparison with equal sample size using 1-sided capability indices. Pearn et al. [4] develops method for comparing 2 
suppliers with unequal sample size which is more efficient than Chou's [3]. In practice, multiple suppliers with unequal sample sizes are requested. So, Hubele et al. [5] present the equality testing of 1-sided PCIs using Wald statistic. For drawbacks of this method, suppliers are tested each pairwise in case of multiple supplier comparison resulting that the significant level value is higher than specified value. After that Manomat and Sudasna-na-Ayudthya [6] develops the supplier comparison method from Hubele's [5] without pairwise comparison. This method is more efficient than Chou's and Hubele's at small sample size. Yu et al. [7] proposes the confident interval of upper process capability index to a fuzzy testing for supplier selection. In addition, many supplier comparison methods are extended to multiple quality characteristics. Pearn and $\mathrm{Wu}$ [8] present the 2 suppliers comparison for multiple characteristics processes using 1-sided PCIs called division method. Wang [9] proposes supplier comparison for multiple linear profiles with 1-sided PCIs. Pearn et al. [10] presents subtraction method which is more efficient than division method. Prasetyo and Kurniati [11] show the example of 2 suppliers comparison proposed by Pearn and $\mathrm{Wu}[8]$.

In quality engineering, quality dimensions presented by Garvin [12] are widely employed to evaluate the quality aspect. Durability, one of the dimensions of quality, is important criterion because it represents the effective service life of the product. Customers require the products that operate satisfactorily over a long period of time [13]. Therefore, manufacturer should focus on this dimension applied in many fields, i.e., preventive maintenance, age of machine and equipment, product lifetime. Lifetime is widely used to measure the durability and commonly modeled with Weibull distribution. The distribution has a variety of shapes providing a good model for small data set [14]. Moreover, it covers a wide class of non-normal distributions [15] such as exponential, lognormal, normal distribution.

However, the existing methods for comparing supplier using 1-sided PCIs bring some misleading result when manufacturer considers the lifetime data because these methods are developed under normality assumption. This research attempts to develop the new method for supplier comparison that can consider the lifetime data. From literature review, the method of Manomat and Sudasna-na-Ayudthya [6] is appropriate to modify to be the new method because it is more comfortable to apply in manufacturing industries. The advantages of this method are comparing multiple suppliers with unequal sample size, no pairwise comparison, and no complex calculation.

To be guideline for developing the new method, this research aims to study the effects of Weibull distribution on supplier comparison proposed by Manomat and Sudasna-na-Ayudthya [6]. This paper study the effect via the 2 measures, i.e., the producer's risk and power of test, determined by Monte Carlo simulation. The $C_{p l}$ index is studied because it corresponds to lifetime data, "larger is the better" quality characteristics.

\section{Materials and methods}

\section{The $C_{p l}$ index}

The PCIs are used to measure performance of the supplier's process or manufacturer regarding specifications. The important assumptions of PCIs are the process that should be under control and normal distributed. For lower-sided specifications, Kane [16] proposes that the $C_{p l}$ assesses the capability of process with lower specification limit $(L S L)$ as shown in Eq. (1). In general, process mean $(\mu)$ and standard deviation $(\sigma)$ are unknown, hence replaced by an estimated sample mean $(\bar{X})$ and standard deviation $(S)$ as shown the estimated $\left(\widehat{C}_{p l}\right)$ in Eq. (2):

$$
\begin{aligned}
& C_{p l}=\frac{\mu-L S L}{3 \sigma}, \\
& \widehat{C}_{p l}=\frac{\bar{X}-L S L}{3 S} .
\end{aligned}
$$

The supplier comparison using $C_{p l}$

This paper adopts supplier comparison method developed by the studied method [6]. The method can be summarized in 6 main steps:

Step 1: Random sample data from suppliers.

Step 2: Calculate $\widehat{C}_{p l}$ of each supplier from Eq. (2). 
Step 3: Rearrange $\widehat{C}_{p l}$ in ascending order. Let $\widehat{C}_{p l, 1}$ be the supplier with the smallest $\widehat{C}_{p l}$ (the $1^{\text {st }}$ supplier), and $\widehat{C}_{p l, k}$ be the suppler with the greatest $\widehat{C}_{p l}$ (the $\mathrm{k}^{\text {th }}$ supplier).

Step 4: Test the equality of the capability index as;

- Define d' as the vector of the difference of $C_{P L}$ between the $1^{\text {st }}$ supplier $\left(C_{P L, 1}\right)$ and other suppliers as:

$\mathbf{d}^{\prime}=\left[\begin{array}{c}C_{P L, I^{-}} C_{P L, 2} \\ C_{P L, 1} C_{P L, 3} \\ \vdots \\ C_{P L, 1} C_{P L, k}\end{array}\right]$;

- $\quad$ Define the test hypothesis and significance level $(\alpha)$ :

$H_{0}: \mathbf{d}^{\prime}=0$ vs. $H_{1}: \mathbf{d}^{\prime} \neq 0$

- $\quad$ Construct the estimated $\mathbf{d}^{\prime}$ matrix $\left(\hat{\mathbf{d}}^{\prime}\right)$ as Eq. (5) due to unknown true parameters of normal distribution:

$\hat{\mathbf{d}}^{\prime}=\left[\begin{array}{c}\widehat{C}_{P L, 1}-\widehat{C}_{P L, 2} \\ \widehat{C}_{P L, 1}-\widehat{C}_{P L, 3} \\ \vdots \\ \widehat{C}_{P L, I}-\widehat{C}_{P L, k}\end{array}\right] ;$

where,

$\widehat{C}_{P L, i}^{\prime}=\sqrt{\frac{n_{i}}{n_{i}-1}} b_{n_{i}-1} \widehat{C}_{P L, i}$

$b_{n_{i}-1}=\sqrt{\frac{2}{n_{i}-1}} \times \frac{\Gamma\left[\left(n_{i}-1\right) / 2\right]}{\Gamma\left[\left(n_{i}-2\right) / 2\right]}$

where $\widehat{C}_{P L, i}^{\prime}$ is the maximum likelihood and unbiased estimator of $C_{P L, i} ; b_{n_{i}-1}$ is correction factor; $n_{i}$ is the sample size of the $i^{\text {th }}$ supplier; $i$ is the $i^{\text {th }}$ supplier $(i=1,2, \ldots, k)$;

- Construct $\mathbf{H}$ and $\mathbf{V}^{\prime}$ matrix as:

$\mathbf{H}=\left[\frac{\partial \mathbf{d}^{\prime}}{\partial C_{P L}}\right]=\left[\begin{array}{ccccc}1 & -1 & 0 & \cdots & 0 \\ 1 & 0 & -1 & \cdots & 0 \\ \vdots & \vdots & \vdots & \ddots & \vdots \\ 1 & 0 & 0 & \cdots & -1\end{array}\right]$

$\mathbf{V}^{\prime}=\operatorname{diag}\left[\frac{1}{n_{1}}\left(\frac{1}{9}+\frac{1}{2} \widehat{C}_{P L, 1}^{2}\right), \frac{1}{n_{2}}\left(\frac{1}{9}+\frac{1}{2} \widehat{C}_{P L, 2}^{2}\right), \ldots, \frac{1}{n_{k}}\left(\frac{1}{9}+\frac{1}{2} \widehat{C}_{P L, k}^{2}\right)\right]$

where $\mathbf{H}$ is the derivative of $\mathbf{d}^{\prime}$ with respect to $C_{P L}$ and $\mathbf{V}^{\prime}$ is matrix of the estimated variances of the estimated $C_{P L}$.

- $\quad$ Calculate the Wald's statistics as:

$W=\widehat{\mathbf{d}}^{\mathrm{T}}\left[\mathbf{H V}^{\prime} \mathbf{H}^{\mathrm{T}}\right]^{-1} \widehat{\mathbf{d}}^{\prime} ;$

- Decide the hypothesis testing as: If the null hypothesis $\left(H_{0}\right)$ is rejected $\left(W>\chi_{\alpha, k-1}^{2}\right)$, the $1^{\text {st }}$ supplier is different from at least one other supplier. The procedure can go to step 5. If $H_{0}$ is not rejected, there is no difference among all suppliers. The procedure can jump to step 6 . 
Step 5: Remove the $1^{\text {st }}$ supplier and replaced by the $2^{\text {nd }}$ supplier. And then the procedure is repeated step 3 to 4 .

Step 6: Conclude the result of supplier comparison.

\section{Simulation experiment}

The producer's risk and power of test are applied to study effects of the supplier comparison. The results of the 2 performance measures are calculated by Monte Carlo simulation with 10,000 iterations [6] via $\mathrm{R}$ studio programming.

\section{Parameters setting}

Since this paper emphasizes on the lifetime, 2-parameter Weibull distribution, e.g., scale $(\delta)$ and shape parameter $(\beta)$, is studied because it widely used for modelling the life of the products or components [17]. The symbol of this distribution is defined as $\mathrm{W}(\delta, \beta)$. The scale parameter defines the scale of the probability distribution. The larger scale parameter leads to the more spread out the distribution. The shape parameter is sensitive to the shape of distribution or process's shape, e.g., rightskewed process, symmetrical-skewed process, and left-skewed process. The Cumulative Distribution Function (CDF) of a Weibull random variable $\mathrm{x}(\mathrm{x} \in[0,+\infty))$ is shown in Eq. (11). Expected values $(E(x))$ and variances $(\operatorname{Var}(x))$ are shown in Eqs. (12) and (13) respectively.

$F(x)=1-\mathrm{e}^{-\left(\frac{x}{\delta}\right)^{\beta}}, x>0, \delta>0, \beta>0$

$\mathrm{E}[x]=\mu=\delta \Gamma(1+1 / \beta)$

$\operatorname{Var}[x]=\delta^{2}\left[\Gamma\left(1+\frac{2}{\beta}\right)-\Gamma\left(1+\frac{1}{\beta}\right)^{2}\right]$

In simulation, this paper studies scale parameter $\delta=1,10$, and 100 because they are the range of commonly spread out the distribution regarding lifetime data. For shape parameter, all process's shapes are studied: $\beta=1,1.5$ (right-skewed process); $\beta=3.6$ (symmetrical process); $\beta=8$ (left-skewed process) as shown in Figure 1. The parameters including details of Weibull distribution are illustrated in Table 1.

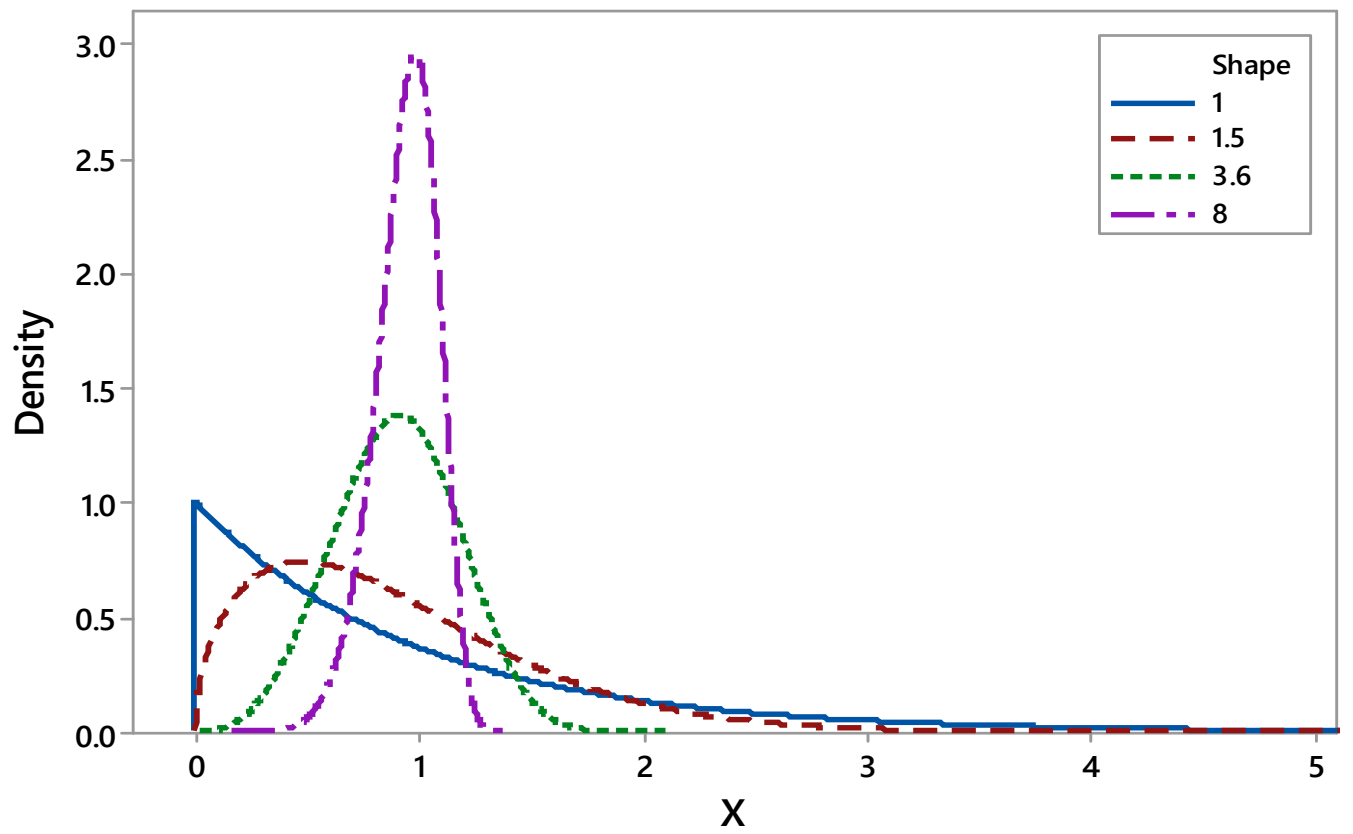

Figure 1 Various shape parameters in this study $(\delta=1)$. 
Table 1 Parameters and their details for simulation.

\begin{tabular}{ccccc}
\hline Parameters & Skewness & Kurtosis & $\boldsymbol{E}(\boldsymbol{x})$ & $\boldsymbol{V} \boldsymbol{a r}(\boldsymbol{x})$ \\
\hline $\mathrm{W}(1,1.0)$ & 1.9971 & 8.9626 & 1.00 & 1.00 \\
$\mathrm{~W}(1,1.5)$ & 1.0714 & 4.3839 & 0.90 & 0.38 \\
$\mathrm{~W}(1,3.6)$ & 0.0004 & 2.7167 & 0.90 & 0.08 \\
W(1,8.0) & -0.5335 & 3.3274 & 0.94 & 0.02 \\
W(10,1.0) & 1.9979 & 9.0116 & 10.00 & 100.00 \\
W(10,1.5) & 1.0714 & 4.3887 & 9.03 & 37.57 \\
W(10,3.6) & 0.0005 & 2.7207 & 9.01 & 7.73 \\
W(10,8.0) & -0.5399 & 3.3385 & 9.42 & 1.95 \\
W(100,1.0) & 1.9950 & 8.9727 & 100.00 & $1,000.00$ \\
W(100,1.5) & 1.0720 & 4.3990 & 90.27 & $3,756.90$ \\
W(100,3.6) & 0.0006 & 2.7143 & 90.11 & 772.95 \\
W(100,8.0) & -0.5308 & 3.3132 & 94.17 & 195.16 \\
\hline
\end{tabular}

To understand the effects, Weibull distribution is compared with normal distribution $\mathrm{N}\left(\mu, \sigma^{2}\right)$ with mean $(\mu)$ and variance $\left(\sigma^{2}\right)$ because the studied method [6] for comparing suppliers is developed under normal distribution. Both distributions are compared each other at the same $E(x)$ and $V(x)$. The $E(x)$ and $\operatorname{Var}(x)$ of normal distribution are $\mu$ and $\sigma^{2}$ respectively. For the example, Weibull distribution with $\delta=1$ and $\beta=1.0$ is compared with normal distribution with $\mu=1.00$ and $\sigma^{2}=1.00$.

This study uses $C_{p l}=1.00$ (capable process), 1.50 (good process), and 2.00 (super process). For normal distribution, the $C_{p l}$ can be determined by the proportion of non-conforming parts $(P N C)$ [4] as:

$P N C=1-\Phi\left(3 C_{p l}\right)$

where $C_{p l}=1.00 ; P N C=1,350 \mathrm{ppm}, C_{p l}=1.50 ; P N C=3.40 \mathrm{ppm}, C_{p l}=2.00 ; P N C=0.001 \mathrm{ppm}$, and ppm is non-conforming parts per million. For Weibull distribution, the $C_{p l}$ can be determined by corresponding $L S L$ value of Weibull distribution with the same PNC [18].

\section{The performance measures}

Producer's risk and power of test are employed to study the effects of supplier comparison. In quality engineering, producer's risk is the probability that a good lot will be rejected, and consumer's risk is the probability of accepting a lot of poor quality (a bad lot). Sometime, consumer's risk is presented as the power of test (1- consumer's risk). The power means the probability of making a correct decision (reject the bad lot). This paper focuses $5 \%$ significance level $(\alpha=0.05)$ since this value is used in the industries commonly. For appropriate supplier comparison, producer's risk should be controlled under 5 $\%$ significance level, and power of test should be closed to 1.00 (maximum value) when sample size is larger.

This paper study 2 and 5 suppliers $(\mathrm{k}=2$ and 5) with sample size $n=15,30,50$, and 100 respectively. The steps of calculating producer's risk can be defined as:

1) Define the $C_{p l}$ of each supplier: All the $C_{p l}$ of suppliers are equal:

- For 2 suppliers, $C_{p l, 1}=C_{p l, 2}=1.00,1.50$, and 2.00 respectively;

- For 5 suppliers, $C_{p l, 1}=C_{p l, 2}=\ldots=C_{p l, 5}=1.00,1.50$, and 2.00 respectively.

2) Take random samples $(n)$ from each supplier.

3) Compare the suppliers using $C_{p l}$ via the studied method [6] with $5 \%$ significance level and record the number of rejecting the null hypothesis.

4) Simulate using Monte Carlo method with iteration of 10,000 times.

5) Calculate producer's risk from Eq. (15):

The producer's risk $=\frac{\text { Number of reject } H_{0}}{10,000 \text { times }}$. 
The steps of calculating power of test can be defined as:

1) Define the $C_{p l}$ of each supplier: The $C_{p l}$ of the $1^{\text {st }}$ supplier is different from other suppliers:

- For 2 suppliers $\left(C_{p l, 1} \neq C_{p l, 2}\right): C_{p l, 1}=1.00$ vs. $C_{p l, 2}=1.50 ; C_{p l, 1}=1.00$ vs. $C_{p l, 2}=2.00$; and $C_{p l, 1}=$ 1.50 vs. $C_{p l, 2}=2.00$;

- For 5 suppliers $\left(C_{p l, 1} \neq C_{p l, 2}=C_{p l, 3}=C_{p l, 4}=C_{p l, 5}\right): C_{p l, 1}=1.00$ vs. $C_{p l, 2}=C_{p l, 3}=C_{p l, 4}=C_{p l, 5}=$ 1.50; $C_{p l, 1}=1.00$ vs. $C_{p l, 2}=C_{p l, 3}=C_{p l, 4}=C_{p l, 5}=2.00$; and $C_{p l, 1}=1.50$ vs. $C_{p l, 2}=C_{p l, 3}=C_{p l, 4}=C_{p l, 5}=2.00$.

2) Take random samples from each supplier.

3) Compare 2 suppliers using $C_{p l}$ via the studied method [6] with $5 \%$ significance level and record the number of rejecting the null hypothesis.

4) Simulate using Monte Carlo method with iteration of 10,000 times.

5) Calculate power of test from Eq. (16):

The power of test $=\frac{\text { Number of reject } H_{0}}{10,000 \text { times }}$.

\section{Results and discussion}

The simulation results are presented in Appendix Tables 1 - 8. For Weibull distribution, the results indicate that shape parameter affects to producer's risk and power of test, but scale parameter does not. This paper presents only the analysis of simulated results for scale parameter $\delta=1$.

For 2 suppliers study, the simulation results of Weibull distribution indicate that producer's risks depend on shape parameter as shown the example $\left(C_{p l, 1}=C_{p l, 2}=1.00\right)$ in Figure 2(a). According to rightskewed process's shape $(\beta<3.6)$, producer's risks are lower than $\alpha=0.05$ in all cases. Since the supplier's process is right-skewed, $\widehat{C}_{p l}$ of each supplier calculated from Eq. (2) is slightly different value leading the slightly possible rejection of true null hypothesis. Then, producer's risks tend to increase and are close to $\alpha=0.05$ in case of symmetrical process $(\beta=3.6)$. However, producer's risks are higher than $\alpha$ $=0.05$ in all cases when left-skewed process $(\beta>3.6)$. The left-skewed process yields much different $\widehat{C}_{p l}$ of each supplier leading the much possible rejection of true null hypothesis. In addition, the results show that larger sample size and higher $C_{p l}$ comparison do not affect the producer's risks. However, the producer's risks are stable in all parameters of normal distribution as shown in Figure 2(b). The risks are controllable under $\alpha=0.05$ range as shown in Figure 2(b).

For power of test, the simulation results for Weibull distribution indicate dependence on shape parameter as shown example $\left(C_{p l, 1}=1.00\right.$ vs. $\left.C_{p l, 2}=1.50\right)$ in Figure 3(a). For right-skewed process $(\beta<$ 3.6), the power of tests do not exceed 0.10 in all cases. The results imply that there is no performance in supplier comparison. Since the processes are right-skewed, the null hypothesis is slightly possible rejected. In case of symmetrical process $(\beta=3.6)$, power of tests tend to increase when sample size is increased, but they do not exceed 0.40 in all cases. Power of tests are close to 1.00 (the maximum value) when sample size is increased in case of left-skewed process $(\beta>3.6)$ since the shape results in the much possible rejection of null hypothesis. This results show that the larger difference of $C_{p l}$ between the supplier (i.e. $C_{p l, l}=1.00$ vs. $C_{p l, 2}=2.00$ ) influence on the increasing power of tests result. Nevertheless, power of tests are stable in all parameters of normal distribution as shown example $\left(C_{p l, 1}=1.00 \mathrm{vs}\right.$. $C_{p l, 2}=$ 1.50) in Figure 3(b).

According to 5 suppliers study as shown in Appendix Tables 5 - 8. For Weibull distribution, process's shape affects the 2 performance measures like 2 suppliers study. However, the number of supplier comparison slightly influences on the 2 performance measures when process is left-skewed. As a result, the results of performance measures for 5 suppliers are greater than 2 suppliers. For normal distribution, the performance measures are stable in all cases like 2 suppliers study. The example results of 5 suppliers study illustrate in Figures 4 and 5.

To summarize of Weibull distribution, process's shapes influence on lower process capability assessment calculated by $C_{p l}$ as Eqs. (1) and (2) because wide-range skewed process is sensitive to process capability [19]. Although process is symmetric $(\beta=3.6)$, the studied method still has no performance in supplier comparison. As a result, the method is inappropriate to compare suppliers when supplier's processes are Weibull distributed. This result corresponds to Swamy et al. [20] and Montgomery [13]. They describe that the result of the process capability analysis may be in error when process is non-normal distributed. 


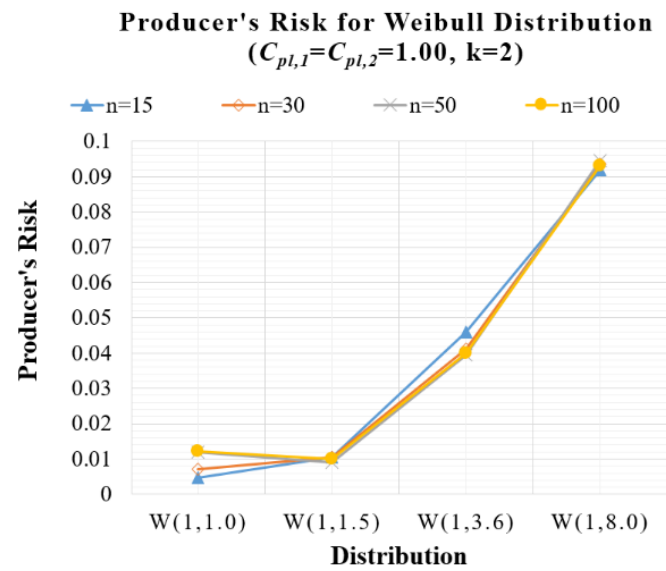

(a)

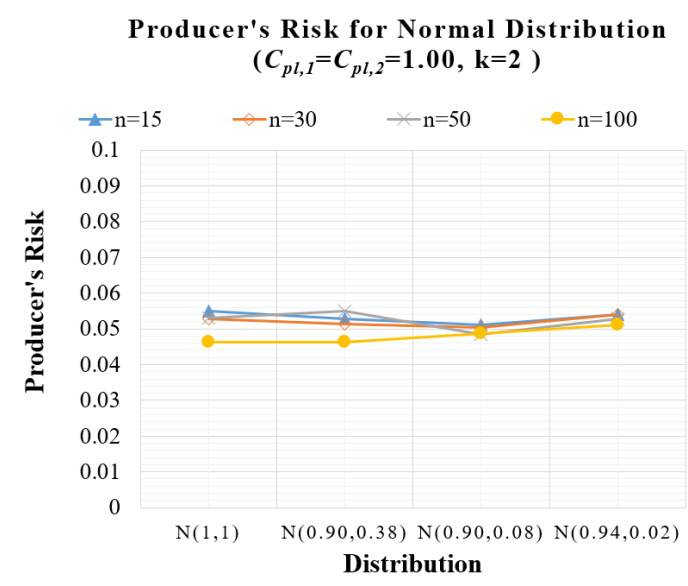

(b)

Figure 2 Producer's risk results in case of $C_{p l, 1}=C_{p l, 2}=1.00(\mathrm{k}=2)$ : (a) Weibull distribution and (b) normal distribution.

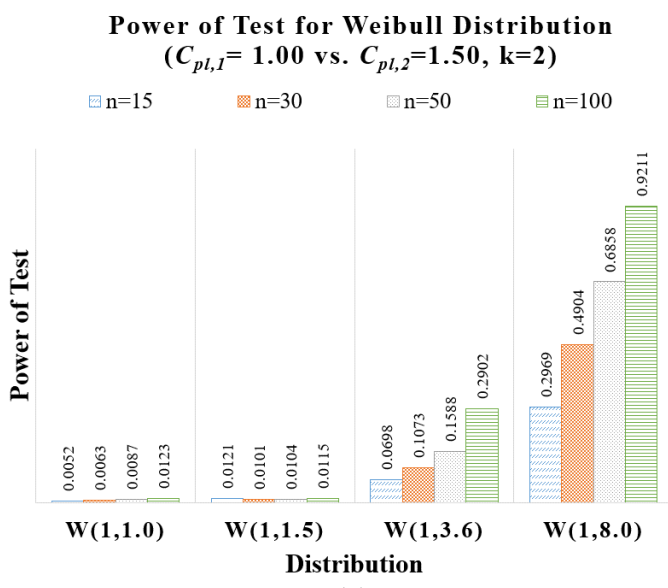

(a)

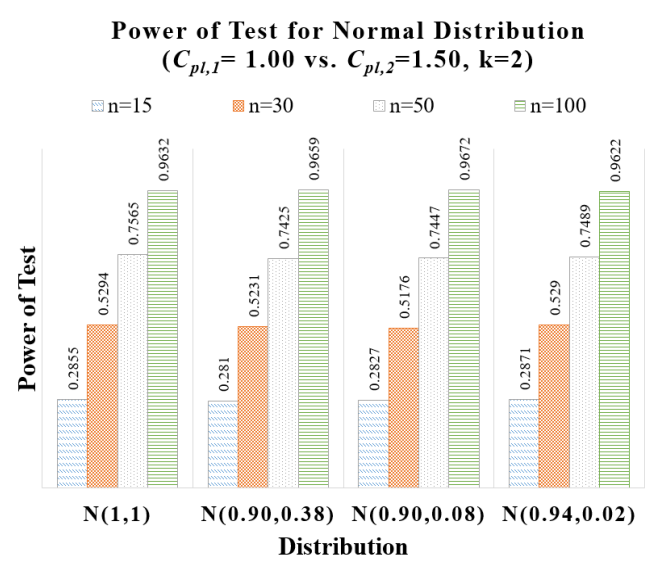

(b)

Figure 3 Power of test results in case of $C_{p l, l}=1.00$ vs. $C_{p l, 2}=1.50(\mathrm{k}=2)$ : (a) Weibull distribution and (b) normal distribution.

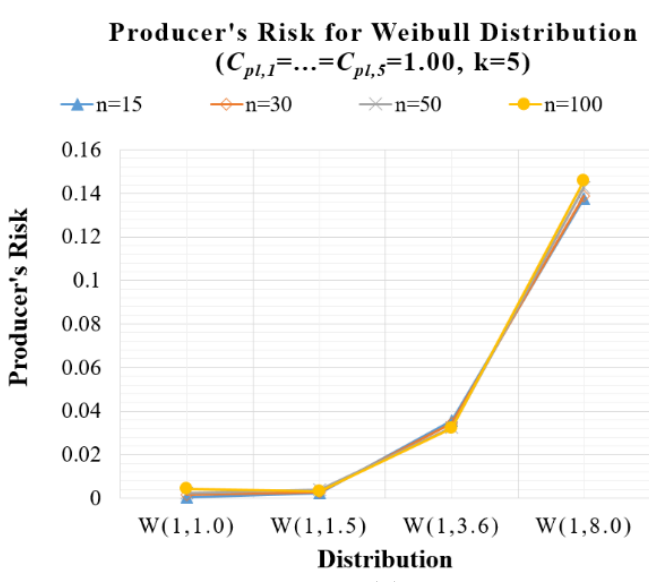

(a)

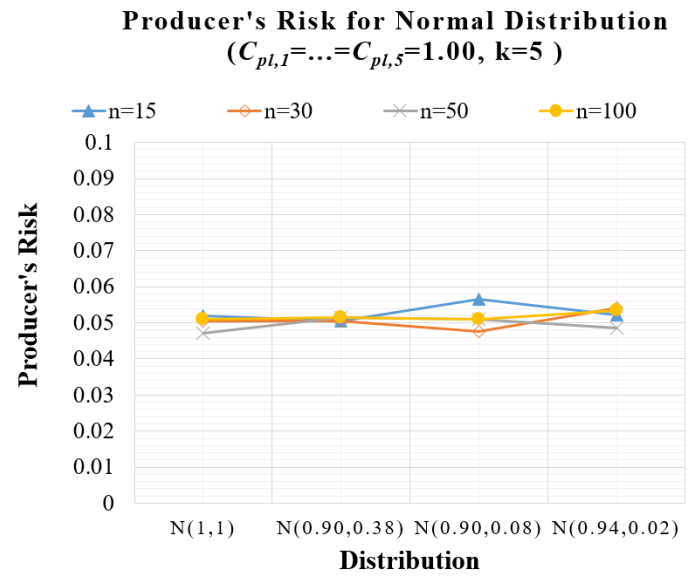

(b)

Figure 4 Producer's risk results in case of $C_{p l, 1}=C_{p l, 2}=1.00(\mathrm{k}=5)$ : (a) Weibull distribution and (b) normal distribution. 


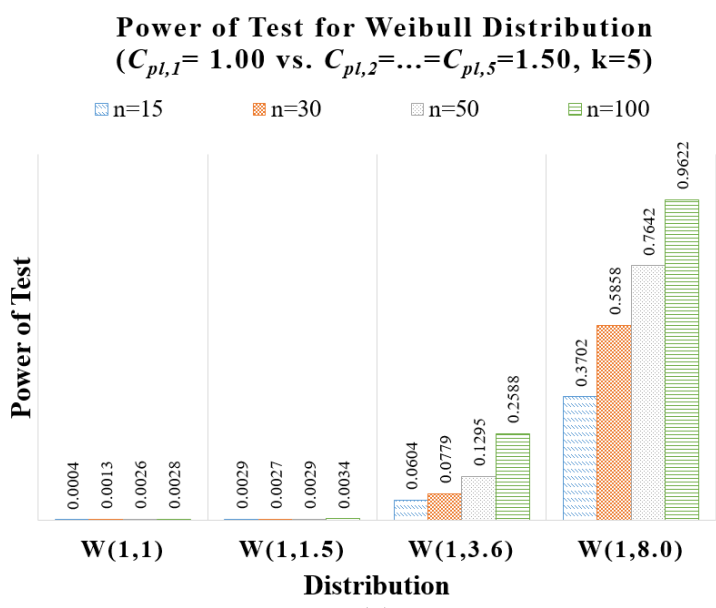

(a)

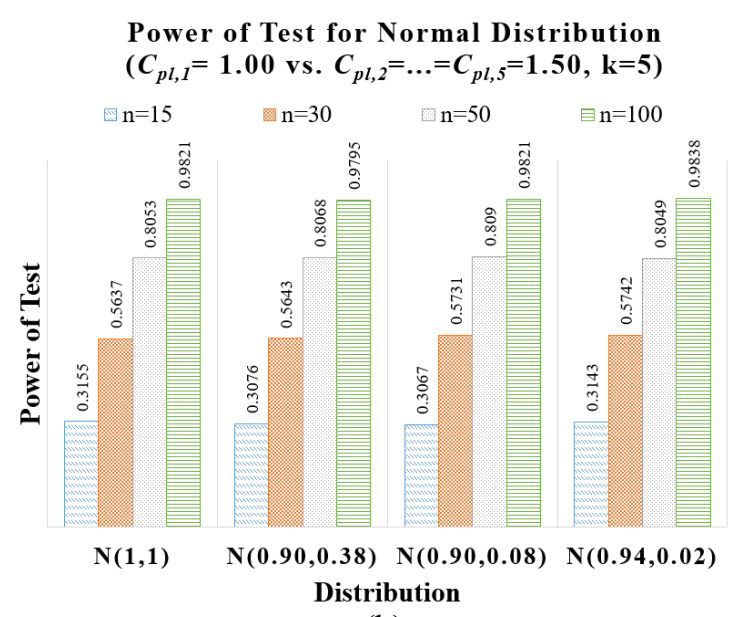

(b)

Figure 5 Power of test results in case of $C_{p l, 1}=1.00$ vs. $C_{p l, 2}=1.50(\mathrm{k}=5)$ : (a) Weibull distribution and (b) normal distribution.

\section{Example}

To better understand the effect, this study presents the supplier comparison via real example. The example is illustrated using real data that is failure time (in hour) of air-conditioning system of 2 processes [21]. This paper assumes that these processes are supplier process of A and B with $L S L=0$. The data of 2 suppliers are summarized in Table 2. The summarized statistic shows that both supplier' processes are Weibull distributed and heavy right-skewed.

Table 2 Summarized statistics for 2 suppliers.

\begin{tabular}{lcc}
\multicolumn{1}{c}{ Summarized Statistic } & Supplier A & Supplier B \\
\hline 1) Descriptive Statistics & & 76.82 \\
- Sample mean $(\bar{X})$ & 64.12 & 63.71 \\
- Sample standard deviation $(S)$ & 62.65 & 27 \\
- Sample size $(n)$ & 24 & $0.80,2.57$ \\
- Skewness, Kurtosis & $1.18,3.25$ & p-value $>0.25$ \\
2) AD test for Weibull distribution & p-value $>0.25$ & $\delta_{B}=79.92, \beta_{B}=1.12$ \\
3) Parameter estimation using maximum & $\delta_{A}=64.79, \beta_{A}=1.02$ & \\
likelihood method &
\end{tabular}

This example is divided into 3 cases: Case I: comparing suppliers using the studied method [6] from real data; Case II: estimating PCIs using Clement percentile method and then comparing suppliers using the studied method [6]; Case III: comparing suppliers using the studied method [6] from transformed data through Johnson transformation method.

The Case II and III apply the methods that assist to handle non-normal distribution. Clement percentile method proposed by [22] is recommended by ISO for non-normal PCIs. This method employs Pearson curve to provide the estimated quantiles $x_{0.00135}, x_{0.50}$ (median) and $x_{0.99865}$ in order to estimate PCIs. Johnson transformation method proposed by Johnson [23] is widely used to transform non-normal distributed data to normal distributed data and easily calculated the estimated PCIs by statistical software (e.g., Minitab). 
Table 3 The supplier comparison results.

\begin{tabular}{|c|c|c|c|}
\hline Types of Result & Case I & Case II & Case III \\
\hline 1) The $\widehat{C}_{p l}$ of supplier $A$ & 0.34 & 0.55 & 1.25 \\
\hline 2) The $\widehat{C}_{p l}$ of supplier B & 0.40 & 0.46 & 0.82 \\
\hline \multicolumn{4}{|l|}{ 3) Supplier comparison results } \\
\hline 3.1) p-value & 0.6127 & 0.5193 & 0.0651 \\
\hline $\begin{array}{l}\text { 3.2) Hypothesis testing result } \\
\text { at } \alpha=0.05 \text { (Selected supplier) }\end{array}$ & $\begin{array}{l}\text { Do not reject } H_{0} \\
\text { (Either one) }\end{array}$ & $\begin{array}{l}\text { Do not reject } H_{0} \\
\quad \text { (Either one) }\end{array}$ & $\begin{array}{l}\text { Do not reject } H_{0} \\
\text { (Either one) }\end{array}$ \\
\hline $\begin{array}{l}\text { 3.3) Hypothesis testing result } \\
\text { at } \alpha=0.10 \text { (Selected supplier) }\end{array}$ & $\begin{array}{l}\text { Do not reject } H_{0} \\
\text { (Either one) }\end{array}$ & $\begin{array}{l}\text { Do not reject } H_{0} \\
\text { (Either one) }\end{array}$ & $\begin{array}{c}\text { Reject } H_{0} \\
\text { (Supplier A) }\end{array}$ \\
\hline
\end{tabular}

The supplier comparison results of 3 cases are illustrated as Table 3. In case I, the null hypothesis cannot be rejected at 5 and $10 \%$ significance level because p-value $(0.6127)$ is greater than 0.05 . There is not enough evidence to conclude that both suppliers are different. Thus, the manufacturer can select either supplier A or B. In case II, supplier A and B are not significant different at 5 and $10 \%$ significance level. But this case is more likely to be significantly different of 2 suppliers than case I because p-value of case II $(0.5193)$ is less than case I.

After transforming the data via Johnson transformation, p-values of supplier A and B obtained from goodness of fit test for normal distribution are 0.925 and 0.982 respectively, which are normally distributed processes. The supplier comparison result of case III ( $p$-value $=0.0651$ ) shows that the hypothesis testing result is same to case I and II at $5 \%$ significance level. However, supplier A and B are significantly different at $10 \%$ significance level so that the manufacturer should select supplier A.

According to the example, Weibull distributed process influences on the $\widehat{C}_{p l}$ calculation, especially heavy right-skewed process. As a result, interpretation of supplier's process is erroneous leading to a possibility misleading results in supplier comparison as shown in the simulation results and case I. Although there are the methods that handle Weibull distributed process as case II and III, the supplier comparison result of each case is not the same and depends also on significance level. The mentioned result lead to the misleading results in some method.

\section{Conclusions}

This study attempts to develop a new supplier comparison method when data are Weibull distributed. To be guideline for developing a new method, this research aims to study the effects of Weibull distribution on supplier comparison using $C_{p l}$ index proposed by Manomat and Sudasna-naAyudthya [6]. The producer's risk and power of test calculated by Monte Carlo simulation are applied in this paper.

The simulation results for Weibull distribution indicate that producer's risks and power of tests are sensitive to process's shape. For right-skewed process, the producer's risks are lower than $\alpha=0.05$ in all cases whereas power of tests do not exceed 0.10 (no performance). For left-skewed process, although the power of tests is close to 1.00 (high performance), the risks are greater than $\alpha=0.05$ in all cases. Finally, the symmetric process yields that the producer's risks are close to $\alpha=0.05$ but the power of tests do not exceed 0.40 (middle performance). The mentioned results lead to a possibility of misleading result in supplier comparison. So, this study points out that the process's shape is an important factor affecting to supplier comparison using $C_{p l}$.

Practically, the manufacturers should examine the distribution of supplier data before comparing suppliers by the studied method [6]. If the supplier's process is Weibull distributed, the result of supplier comparison is likely to mislead result as illustrated in the simulated results and case I of the example. In addition, although process is symmetric, the studied method [6] has no performance.

To handle Weibull distributed process, Johnson transformation and Clement percentile method, popular method in many industries, are applied in this study. The example shows that the supplier comparison results are not the same at $10 \%$ significance level as illustrated in case II and III. The supplier comparison results can be different. So, the manufacturers should be aware in supplier comparison with Weibull distributed process.

Regarding lifetime, although the data are an important criterion for comparing supplier, the studied method is inappropriate to apply. Therefore, the further research will develop the new method based on the studied method [6] for comparing multiple suppliers in case of Weibull distributed process to apply 
with lifetime data accurately and comfortably. When qualified supplier is selected exactly, raw materials and parts from the supplier will be used to produce quality products and service resulting that customers are satisfied.

\section{Acknowledgements}

This paper is supported by the Department of Industrial Engineering, Faculty of Engineering, Kasetsart University and Department of Industrial Engineering, School of Engineering, University of Phayao, Thailand.

\section{References}

[1] P Sureeyatanapas, K Sriwattananusart, T Niyamosoth, W Sessomboon and S Arunyanart. Supplier selection towards uncertain and unavailable information: An extension of TOPSIS method. Oper. Res. Perspect. 2018; 5, 69-79.

[2] M Abdolshah. A review of quality criteria supporting supplier selection. Qual. Reliab. Eng. Int. 2013; 2013, 621073.

[3] YM Chou. Selecting a better supplier by testing process capability indices. Qual. Eng. 1994; 6, 42738.

[4] WL Pearn, HN Hung and YC Cheng. Supplier selection for one-side processes with unequal sample sizes. Eur. J. Oper. Res. 2009; 195, 381-93.

[5] NF Hubele, A Berrado and ES Gel. A Wald test for comparing multiple capability indices. J. Qual. Technol. 2005; 37, 304-7.

[6] S Manomat and P Sudasna-na-Ayudthya. The method for selecting multiple suppliers using onesided specification limit's capability index (in Thai). Khon Kaen Univ. Eng. J. 2009; 36, 313-21.

[7] CM Yu, KS Chen, KK Lai and CH Hsu. Fuzzy supplier selection method based on smaller-thebetter quality characteristic. Appl. Sci. 2020; 10, 3635.

[8] WL Pearn and $\mathrm{CH}$ Wu. Supplier selection for multiple-characteristics processes with one-sided specifications. Qual. Technol. Quant. Manag. 2013; 10, 133-9.

[9] FK Wang. Supplier selection for multiple linear profiles with one-sided specifications. Qual. Reliab. Eng. Int. 2016; 32, 257-68.

[10] WL Pearn, $\mathrm{CH}$ Wu and CC Chuang. An effective powerful test for one-sided supplier selection problem with multiple independent characteristics. Qual. Technol. Quant. Manag. 2016; 13, 182-96.

[11] EB Prasetyo and N Kurniati. Supplier selection based on capabilities index for multiple characteristics with one sided specification. Sinergi 2018; 22, 113-9.

[12] DA Garvin. Completing in the eight dimensions of quality. Harv. Bus. Rev. 1987; 87, 101-9.

[13] DC Montgomery .Introduction to statistical quality control. $8^{\text {th }}$ eds. John Weiley \& Sons, New York, 2020.

[14] B Dodson. The Weibull analysis handbook. $2^{\text {nd }}$ eds. American Society for Quality, Quality Press, Milwaukee, 2006.

[15] O Senvar and B Sennaroglu. Comparing performances of Clements, Box-cox, Johnson methods with Weibull distributions for assessing process capability. J. Ind. Eng. Manag. 2016; 9, 634-56.

[16] VE Kane. Process capability indices. J. Qual. Technol. 1986; 18, 41-52.

[17] R Jiang and DNP Murthy. A study of Weibull shape parameter: Properties and significance. Reliab. Eng. Syst. Saf. 2011; 96, 1619-26.

[18] PH Lui and FL Chen. Process capability of non-normal process data using the Burr XII distribution. Int. J. Adv. Manuf. Technol. 2006; 27, 975-84.

[19] H Wang, J Yang and S Hao. Two inverse normalizing transformation method for the process capability analysis of non-normal process data. Comput. Ind. Eng. 2016; 102, 88-98.

[20] DR Swamy, P Nagesh and Y Wooluru. Process capability indices for non-normal distribution- a review. In: Proceedings of the International Conference on Operations Management and Research, Mysuru, India. 2016, p. 1-13.

[21] F Proschan. Theoretical explanation of observed decreasing failure rate. Technometrics 1963; 5, 375-83.

[22] JA Clement. Process capability calculations for non-normal distributions. Qual. Prog. 1989; 22, 95100.

[23] NL Johnson. System of frequency curves generated by methods of translation. Biometrika 1949; 36, 149-76. 


\section{Appendices}

Appendix Table 1 The producer's risk results for Weibull distribution with supplier k=2.

\begin{tabular}{|c|c|c|c|c|c|c|c|c|c|c|c|c|}
\hline \multicolumn{5}{|c|}{$C_{p l, 1}=C_{p l, 2}=1.00(P N C=1349.89 \mathrm{ppm})$} & \multicolumn{4}{|c|}{$C_{p l, 1}=C_{p l, 2}=1.5(P N C=3.398 \mathrm{ppm})$} & \multicolumn{4}{|c|}{$C_{p l, 1}=C_{p l, 2}=2.00(P N C=0.001 \mathrm{ppm})$} \\
\hline Sample Size & $W(1,1.0)$ & $W(1,1.5)$ & $\mathrm{W}(1,3.6)$ & $W(1,8.0)$ & $W(1,1.0)$ & $W(1,1.5)$ & $W(1,3.6)$ & $W(1,8.0)$ & $W(1,1.0)$ & $W(1,1.5)$ & $W(1,3.6)$ & $W(1,8.0)$ \\
\hline $\mathrm{n}=15$ & 0.0048 & 0.0106 & 0.0459 & 0.0919 & 0.0046 & 0.0143 & 0.0442 & 0.0893 & 0.0067 & 0.0106 & 0.0426 & 0.0829 \\
\hline $\mathrm{n}=30$ & 0.0070 & 0.0106 & 0.0412 & 0.0937 & 0.0082 & 0.0097 & 0.0415 & 0.0907 & 0.0068 & 0.0107 & 0.0386 & 0.0866 \\
\hline $\mathrm{n}=50$ & 0.0120 & 0.0091 & 0.0395 & 0.0946 & 0.0089 & 0.0089 & 0.0402 & 0.0900 & 0.0079 & 0.0122 & 0.0408 & 0.0872 \\
\hline $\mathrm{n}=100$ & 0.0122 & 0.0101 & 0.0400 & 0.0932 & 0.0110 & 0.0128 & 0.0372 & 0.0840 & 0.0097 & 0.0120 & 0.0375 & 0.0847 \\
\hline Sample Size & W(10,1.0) & $W(10,1.5)$ & $\mathrm{W}(10,3.6)$ & $\mathrm{W}(\mathbf{1 0 , 8 . 0 )}$ & $\mathrm{W}(10,1.0)$ & $\mathrm{W}(10,1.5)$ & $W(10,3.6)$ & W(10,8.0) & $W(10,1.0)$ & $\mathrm{W}(10,1.5)$ & $\mathrm{W}(10,3.6)$ & $W(10,8.0)$ \\
\hline $\mathrm{n}=15$ & 0.0054 & 0.0110 & 0.0399 & 0.0989 & 0.0059 & 0.0138 & 0.0442 & 0.0845 & 0.0048 & 0.0111 & 0.0434 & 0.0877 \\
\hline $\mathrm{n}=30$ & 0.0061 & 0.0126 & 0.0379 & 0.0968 & 0.0069 & 0.0123 & 0.0450 & 0.0883 & 0.0070 & 0.0114 & 0.0405 & 0.0862 \\
\hline $\mathrm{n}=50$ & 0.0106 & 0.0119 & 0.0400 & 0.0982 & 0.0089 & 0.0105 & 0.0380 & 0.0859 & 0.0086 & 0.0111 & 0.0388 & 0.0903 \\
\hline $\mathrm{n}=100$ & 0.0097 & 0.0110 & 0.0367 & 0.0960 & 0.0117 & 0.0116 & 0.0343 & 0.0841 & 0.0091 & 0.0121 & 0.0409 & 0.0896 \\
\hline Sample Size & W(100,1.0) & $\mathrm{W}(\mathbf{1 0 0 , 1 . 5 )}$ & $\mathrm{W}(100,3.6)$ & $\mathrm{W}(\mathbf{1 0 0 , 8 . 0 )}$ & $\mathrm{W}(\mathbf{1 0 0 , 1 . 0 )}$ & $\mathrm{W}(\mathbf{1 0 0 , 1 . 5 )}$ & $\mathrm{W}(\mathbf{1 0 0 , 3 . 6 )}$ & W(100,8.0) & $\mathrm{W}(\mathbf{1 0 0 , 1 . 0 )}$ & $\mathrm{W}(\mathbf{1 0 0 , 1 . 5 )}$ & $\mathrm{W}(\mathbf{1 0 0 , 3 . 6 )}$ & $W(100,8.0)$ \\
\hline $\mathrm{n}=15$ & 0.0061 & 0.0116 & 0.0441 & 0.0917 & 0.0054 & 0.0113 & 0.0436 & 0.0862 & 0.0041 & 0.0123 & 0.0438 & 0.0871 \\
\hline $\mathrm{n}=30$ & 0.0075 & 0.0118 & 0.0401 & 0.0971 & 0.0062 & 0.0123 & 0.0388 & 0.0837 & 0.0089 & 0.0118 & 0.0393 & 0.0859 \\
\hline $\mathrm{n}=50$ & 0.0094 & 0.0109 & 0.0389 & 0.0984 & 0.0085 & 0.0110 & 0.0370 & 0.0860 & 0.0083 & 0.0134 & 0.0370 & 0.0840 \\
\hline $\mathrm{n}=100$ & 0.0110 & 0.0127 & 0.0389 & 0.0967 & 0.0123 & 0.0090 & 0.0364 & 0.0906 & 0.0132 & 0.0125 & 0.0386 & 0.0909 \\
\hline
\end{tabular}

Appendix Table 2 The producer's risk results for normal distribution with supplier $\mathrm{k}=2$.

\begin{tabular}{|c|c|c|c|c|c|c|c|c|c|c|c|c|}
\hline \multicolumn{5}{|c|}{$C_{p l, 1}=C_{p l, 2}=1.00(P N C=1349.89 \mathrm{ppm})$} & \multicolumn{4}{|c|}{$C_{p l, 1}=C_{p l, 2}=1.5(P N C=3.398 \mathrm{ppm})$} & \multicolumn{4}{|c|}{$C_{p l, 1}=C_{p l, 2}=2.00(P N C=0.001 \mathrm{ppm})$} \\
\hline $\begin{array}{c}\text { Sample } \\
\text { Size }\end{array}$ & $\begin{array}{c}\mathrm{N} \\
(\mathbf{1 , 1}) \\
\end{array}$ & $\begin{array}{c}\mathrm{N} \\
(0.90,0.38) \\
\end{array}$ & $\begin{array}{c}\mathrm{N} \\
(0.90,0.08) \\
\end{array}$ & $\begin{array}{c}\mathrm{N} \\
(0.94,0.02) \\
\end{array}$ & $\begin{array}{c}N \\
(1,1)\end{array}$ & $\begin{array}{c}\mathrm{N} \\
(0.90,0.38) \\
\end{array}$ & $\begin{array}{c}\mathrm{N} \\
(0.90,0.08)\end{array}$ & $\begin{array}{c}\mathrm{N} \\
(0.94,0.02) \\
\end{array}$ & $\begin{array}{c}N \\
(\mathbf{1}, \mathbf{1}) \\
\end{array}$ & $\begin{array}{c}N \\
(0.90,0.38) \\
\end{array}$ & $\begin{array}{c}\mathrm{N} \\
(0.90,0.08)\end{array}$ & $\begin{array}{c}\mathrm{N} \\
(0.94,0.02) \\
\end{array}$ \\
\hline $\mathrm{n}=15$ & 0.0549 & 0.0527 & 0.0510 & 0.0541 & 0.0539 & 0.0524 & 0.0504 & 0.0539 & 0.0554 & 0.0567 & 0.0529 & 0.0519 \\
\hline $\mathrm{n}=30$ & 0.0527 & 0.0513 & 0.0505 & 0.0541 & 0.0508 & 0.0498 & 0.0546 & 0.0500 & 0.0511 & 0.0547 & 0.0563 & 0.0543 \\
\hline $\mathrm{n}=50$ & 0.0531 & 0.0549 & 0.0484 & 0.0529 & 0.0508 & 0.0567 & 0.0523 & 0.0518 & 0.0528 & 0.0519 & 0.0515 & 0.0522 \\
\hline $\mathrm{n}=100$ & 0.0462 & 0.0464 & 0.0488 & 0.0512 & 0.0524 & 0.0521 & 0.0527 & 0.0504 & 0.0540 & 0.0467 & 0.0497 & 0.0511 \\
\hline $\begin{array}{c}\text { Sample } \\
\text { Size }\end{array}$ & $\underset{(10,10)}{N}$ & $\begin{array}{c}\mathrm{N} \\
(9.03,37.57)\end{array}$ & $\begin{array}{c}\mathrm{N} \\
(9.01,7.73)\end{array}$ & $\begin{array}{c}\mathrm{N} \\
(\mathbf{9 . 4 2 , 1 . 9 5 )}\end{array}$ & $\begin{array}{c}\mathrm{N} \\
(\mathbf{1 0 , 1 0})\end{array}$ & $\begin{array}{c}\mathrm{N} \\
(9.03,37.57)\end{array}$ & $\begin{array}{c}\mathrm{N} \\
(9.01,7.73)\end{array}$ & $\begin{array}{c}\mathrm{N} \\
(\mathbf{9 . 4 2 , 1 . 9 5 )}\end{array}$ & $\begin{array}{c}\mathbf{N} \\
(\mathbf{1 0 , 1 0})\end{array}$ & $\begin{array}{c}\mathrm{N} \\
(9.03,37.57)\end{array}$ & $\begin{array}{c}\mathrm{N} \\
(9.01,7.73)\end{array}$ & $\begin{array}{c}\mathrm{N} \\
(9.42,1.95)\end{array}$ \\
\hline $\mathrm{n}=15$ & 0.0502 & 0.0513 & 0.0521 & 0.0529 & 0.0547 & 0.0510 & 0.0535 & 0.0576 & 0.0532 & 0.0517 & 0.0495 & 0.0515 \\
\hline $\mathrm{n}=30$ & 0.0536 & 0.0515 & 0.0509 & 0.0509 & 0.0508 & 0.0527 & 0.0517 & 0.0508 & 0.0550 & 0.0493 & 0.0520 & 0.0483 \\
\hline $\mathrm{n}=50$ & 0.0514 & 0.0507 & 0.0486 & 0.0465 & 0.0551 & 0.0503 & 0.0538 & 0.0524 & 0.0482 & 0.0506 & 0.0495 & 0.0520 \\
\hline $\mathrm{n}=100$ & 0.0498 & 0.0485 & 0.0521 & 0.0483 & 0.0550 & 0.0537 & 0.0496 & 0.0539 & 0.0526 & 0.0482 & 0.0541 & 0.0518 \\
\hline $\begin{array}{c}\text { Sample } \\
\text { Size }\end{array}$ & $\begin{array}{c}N \\
(100.1000)\end{array}$ & $\begin{array}{c}N \\
9027376900\end{array}$ & $\begin{array}{c}N \\
\end{array}$ & $\begin{array}{c}N \\
\end{array}$ & $\begin{array}{c}\mathbf{N} \\
(1001000)\end{array}$ & $\begin{array}{c}\mathbf{N} \\
9027376900\end{array}$ & $\begin{array}{c}\mathrm{N} \\
901177295)\end{array}$ & 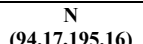 & $\begin{array}{c}\mathrm{N} \\
(\mathbf{1 0 0 . 1 0 0 0 )}\end{array}$ & $\begin{array}{c}N \\
\end{array}$ & $\begin{array}{c}\mathrm{N} \\
\mathbf{9}\end{array}$ & $\begin{array}{c}\mathrm{N} \\
(94.17 .195 .16)\end{array}$ \\
\hline $\begin{array}{c}\text { Size } \\
\mathrm{n}=15\end{array}$ & $\frac{(\mathbf{1 0 0}, \mathbf{1 0 0 0})}{0.055}$ & $\frac{(\mathbf{9 0 . 2 7 , 3 7 5 6 . 9 0 )}}{0.0559}$ & $\begin{array}{c}(\mathbf{9 0 . 1 1 , 7 7 2 . 9 5 )} \\
0.0526\end{array}$ & $\begin{array}{c}(\mathbf{9 4 . 1 7 , 1 9 5 . 1 6 )} \\
0.057\end{array}$ & $\frac{(\mathbf{1 0 0}, \mathbf{1 0 0 0})}{0.0521}$ & $\begin{array}{c}\mathbf{( 9 0 . 2 7 , 3 7 5 6 . 9 0 )} \\
0.0551\end{array}$ & $\frac{(\mathbf{9 0 . 1 1}, \mathbf{7 7 2 . 9 5 )}}{0.0555}$ & $\frac{(94.17,195.16)}{0.0532}$ & $\frac{(100,1000)}{0.0568}$ & $\begin{array}{c}(90.27,5756.90) \\
0.0533\end{array}$ & $\frac{(90.11,7 / 2.95)}{0.0544}$ & $\frac{(94.17,195.16)}{0.0545}$ \\
\hline $\mathrm{n}=30$ & 0.0483 & 0.0476 & 0.056 & 0.0534 & 0.051 & 0.0514 & 0.0537 & 0.0498 & 0.0532 & 0.0522 & 0.0464 & 0.0523 \\
\hline $\mathrm{n}=50$ & 0.0536 & 0.0512 & 0.0518 & 0.0526 & 0.0555 & 0.0522 & 0.0524 & 0.0547 & 0.0508 & 0.0511 & 0.0495 & 0.055 \\
\hline $\mathrm{n}=100$ & 0.0516 & 0.0506 & 0.0496 & 0.0505 & 0.0489 & 0.0507 & 0.0503 & 0.0502 & 0.0497 & 0.0507 & 0.0488 & 0.0467 \\
\hline
\end{tabular}

Appendix Table 3 The power of test results for Weibull distribution with supplier $\mathrm{k}=2$.

\begin{tabular}{|c|c|c|c|c|c|c|c|c|c|c|c|c|}
\hline \multicolumn{5}{|c|}{$C_{p l, 1}=1.00$ vs. $C_{p l, 2}=1.50$} & \multicolumn{4}{|c|}{$C_{p l, 1}=1.00$ vs. $C_{p l, 2}=2.00$} & \multicolumn{4}{|c|}{$C_{p l, 1}=1.50$ vs. $C_{p l, 2}=2.00$} \\
\hline Sample Size & $\mathrm{W}(1,1)$ & $W(1,1.5)$ & $W(1,3.6)$ & $W(1,8.0)$ & $W(1,1)$ & $\mathrm{W}(1,1.5)$ & $W(1,3.6)$ & $W(1,8.0)$ & $\mathrm{W}(1,1)$ & $W(1,1.5)$ & $W(1,3.6)$ & $\mathrm{W}(\mathbf{1 , 8 . 0 )}$ \\
\hline $\mathrm{n}=15$ & 0.0052 & 0.0121 & 0.0698 & 0.2969 & 0.0057 & 0.0105 & 0.0865 & 0.4775 & 0.0056 & 0.0122 & 0.0475 & 0.1231 \\
\hline $\mathrm{n}=30$ & 0.0063 & 0.0101 & 0.1073 & 0.4904 & 0.0072 & 0.0106 & 0.1421 & 0.7669 & 0.0063 & 0.0117 & 0.0435 & 0.1766 \\
\hline $\mathrm{n}=50$ & 0.0087 & 0.0104 & 0.1588 & 0.6858 & 0.0090 & 0.0125 & 0.2157 & 0.9169 & 0.0089 & 0.0109 & 0.0449 & 0.2283 \\
\hline $\mathrm{n}=100$ & 0.0123 & 0.0115 & 0.2902 & 0.9211 & 0.0111 & 0.0120 & 0.3892 & 0.9959 & 0.0121 & 0.0112 & 0.0454 & 0.3657 \\
\hline Sample Size & $\mathrm{W}(10,1.0)$ & $W(10,1.5)$ & $\mathrm{W}(10,3.6)$ & $\mathrm{W}(\mathbf{1 0 , 8 . 0 )}$ & $W(10,1.0)$ & $\mathrm{W}(10,1.5)$ & $\mathrm{W}(10,3.6)$ & $\mathrm{W}(\mathbf{1 0 , 8 . 0 )}$ & $\mathrm{W}(10,1.0)$ & $W(10,1.5)$ & $\mathrm{W}(10,3.6)$ & $W(10,8.0)$ \\
\hline $\mathrm{n}=15$ & 0.0056 & 0.0111 & 0.0721 & 0.2932 & 0.0048 & 0.0106 & 0.0886 & 0.4852 & 0.0047 & 0.0125 & 0.0449 & 0.1298 \\
\hline $\mathrm{n}=30$ & 0.0074 & 0.0111 & 0.1133 & 0.4930 & 0.0066 & 0.0103 & 0.1375 & 0.7633 & 0.0075 & 0.0130 & 0.0448 & 0.1683 \\
\hline $\mathrm{n}=50$ & 0.0091 & 0.0106 & 0.1600 & 0.6921 & 0.0086 & 0.0118 & 0.2075 & 0.9230 & 0.0079 & 0.0111 & 0.0428 & 0.2299 \\
\hline $\mathrm{n}=100$ & 0.0100 & 0.0116 & 0.2950 & 0.9175 & 0.0117 & 0.0104 & 0.3899 & 0.9966 & 0.0123 & 0.0105 & 0.0469 & 0.3631 \\
\hline Sample Size & $\mathrm{W}(\mathbf{1 0 0 , 1 . 0 )}$ & W(100,1.5) & $\mathrm{W}(100,3.6)$ & $\mathrm{W}(\mathbf{1 0 0 , 8 . 0 )}$ & W(100,1.0) & $\mathrm{W}(100,1.5)$ & $W(100,3.6)$ & $\mathrm{W}(\mathbf{1 0 0 , 8 . 0 )}$ & $\mathrm{W}(\mathbf{1 0 0 , 1 . 0 )}$ & W(100,1.5) & $W(100,3.6)$ & $W(100,8.0)$ \\
\hline $\mathrm{n}=15$ & 0.0064 & 0.0109 & 0.077 & 0.2881 & 0.0053 & 0.0108 & 0.0879 & 0.4811 & 0.0066 & 0.0147 & 0.046 & 0.1242 \\
\hline $\mathrm{n}=30$ & 0.0067 & 0.0107 & 0.1101 & 0.4915 & 0.0081 & 0.0119 & 0.1334 & 0.7603 & 0.0087 & 0.0091 & 0.0426 & 0.1704 \\
\hline $\mathrm{n}=50$ & 0.0089 & 0.0124 & 0.1622 & 0.6853 & 0.0093 & 0.0118 & 0.2131 & 0.9229 & 0.0101 & 0.0108 & 0.0419 & 0.2268 \\
\hline $\mathrm{n}=100$ & 0.0122 & 0.0114 & 0.2891 & 0.9227 & 0.0138 & 0.0120 & 0.3905 & 0.9971 & 0.0148 & 0.0141 & 0.0424 & 0.3647 \\
\hline
\end{tabular}


Appendix Table 4 The power of test results for normal distribution with supplier $\mathrm{k}=2$.

\begin{tabular}{|c|c|c|c|c|c|c|c|c|c|c|c|c|}
\hline \multicolumn{5}{|c|}{$C_{p l, 1}=1.00$ vs. $C_{p l, 2}=1.50$} & \multicolumn{4}{|c|}{$C_{p l, 1}=1.00$ vs. $C_{p l, 2}=2.00$} & \multicolumn{4}{|c|}{$C_{p l, 1}=1.50$ vs. $C_{p l, 2}=2.00$} \\
\hline $\begin{array}{c}\text { Sample } \\
\text { Size }\end{array}$ & $\mathbf{N}(1,1)$ & $\mathrm{N}(\mathbf{0 . 9 0 , 0 . 3 8 )}$ & $\mathrm{N}(0.90,0.08)$ & $\mathrm{N}(0.94,0.02)$ & $N(1,1)$ & $\mathrm{N}(\mathbf{0 . 9 0 , 0 . 3 8 )}$ & $\mathrm{N}(\mathbf{0 . 9 0 , 0 . 0 8 )}$ & $\mathrm{N}(\mathbf{0 . 9 4 , 0 . 0 2 )}$ & $N(1,1)$ & $\mathrm{N}(\mathbf{0 . 9 0 , 0 . 3 8 )}$ & $\mathrm{N}(\mathbf{0 . 9 0 , 0 . 0 8 )}$ & $\mathrm{N}(0.94,0.02)$ \\
\hline $\mathrm{n}=15$ & 0.2855 & 0.2810 & 0.2827 & 0.2871 & 0.6703 & 0.6673 & 0.6723 & 0.6808 & 0.1771 & 0.1692 & 0.1729 & 0.1677 \\
\hline $\mathrm{n}=30$ & 0.5294 & 0.5231 & 0.5176 & 0.5290 & 0.9401 & 0.9383 & 0.9345 & 0.9402 & 0.3078 & 0.3208 & 0.3097 & 0.3179 \\
\hline $\mathrm{n}=50$ & 0.7565 & 0.7425 & 0.7447 & 0.7489 & 0.9940 & 0.9949 & 0.9960 & 0.9958 & 0.4940 & 0.4949 & 0.4972 & 0.4994 \\
\hline $\mathrm{n}=100$ & 0.9632 & 0.9659 & 0.9672 & 0.9622 & 1.0000 & 1.0000 & 1.0000 & 1.0000 & 0.7819 & 0.7771 & 0.7857 & 0.7910 \\
\hline $\begin{array}{c}\text { Sample } \\
\text { Size }\end{array}$ & $\mathrm{N}(10,10)$ & $N(9.03,37.57)$ & $\mathrm{N}(9.01,7.73)$ & $\mathrm{N}(9.42,1.95)$ & $\mathrm{N}(10,10)$ & $\mathrm{N}(\mathbf{9 . 0 3 , 3 7 . 5 7 )}$ & $\mathrm{N}(9.01,7.73)$ & $\mathrm{N}(9.42,1.95)$ & $\mathrm{N}(\mathbf{1 0 , 1 0 )}$ & $\mathrm{N}(\mathbf{9 . 0 3 , 3 7 . 5 7 )}$ & $\mathrm{N}(9.01,7.73)$ & $\mathrm{N}(9.42,1.95)$ \\
\hline $\mathrm{n}=15$ & 0.289 & 0.287 & 0.286 & 0.277 & 0.673 & 0.669 & 0.675 & 0.674 & 0.176 & 0.180 & 0.177 & 0.178 \\
\hline $\mathrm{n}=30$ & 0.527 & 0.528 & 0.527 & 0.531 & 0.940 & 0.936 & 0.939 & 0.942 & 0.304 & 0.319 & 0.320 & 0.313 \\
\hline $\mathrm{n}=50$ & 0.750 & 0.751 & 0.757 & 0.754 & 0.996 & 0.996 & 0.995 & 0.995 & 0.494 & 0.492 & 0.482 & 0.483 \\
\hline $\mathrm{n}=100$ & 0.962 & 0.961 & 0.964 & 0.963 & 1.000 & 1.000 & 1.000 & 1.000 & 0.785 & 0.787 & 0.783 & 0.785 \\
\hline $\begin{array}{c}\text { Sample } \\
\text { Size }\end{array}$ & $\begin{array}{c}N \\
N \\
(100,1000)\end{array}$ & $\begin{array}{c}\mathrm{N} \\
(90.27,3756.90) \\
\end{array}$ & $\begin{array}{c}\mathrm{N} \\
(\mathbf{9 0 . 1 1 , 7 7 2 . 9 5 )}\end{array}$ & $\begin{array}{c}\mathrm{N} \\
(94.17,195.16)\end{array}$ & $\begin{array}{c}N \\
N \\
(100,1000)\end{array}$ & $\begin{array}{c}\mathrm{N} \\
(\mathbf{9 0 . 2 7 , 3 7 5 6 . 9 0 )} \\
\end{array}$ & $\begin{array}{c}\mathrm{N} \\
(90.11,772.95)\end{array}$ & $\begin{array}{c}\mathrm{N} \\
(94.17,195.16) \\
\end{array}$ & $\begin{array}{c}\mathrm{N} \\
(\mathbf{1 0 0 , 1 0 0 0 )}\end{array}$ & $\begin{array}{c}\mathrm{N} \\
(\mathbf{9 0 . 2 7 , 3 7 5 6 . 9 0 )} \\
\end{array}$ & $\begin{array}{c}\mathrm{N} \\
(\mathbf{9 0 . 1 1 , 7 7 2 . 9 5 )}\end{array}$ & $\begin{array}{c}\mathrm{N} \\
(94.17,195.16) \\
\end{array}$ \\
\hline $\mathrm{n}=15$ & 0.2884 & 0.2846 & 0.2862 & 0.2832 & 0.6752 & 0.6766 & 0.6748 & 0.6711 & 0.165 & 0.1758 & 0.1746 & 0.1638 \\
\hline $\mathrm{n}=30$ & 0.5187 & 0.5333 & 0.5269 & 0.5224 & 0.9408 & 0.9403 & 0.9369 & 0.9429 & 0.3155 & 0.3214 & 0.3181 & 0.3164 \\
\hline $\mathrm{n}=50$ & 0.7513 & 0.7544 & 0.7483 & 0.7499 & 0.9954 & 0.9960 & 0.9953 & 0.9952 & 0.4877 & 0.4953 & 0.4871 & 0.4923 \\
\hline $\mathrm{n}=100$ & 0.9658 & 0.9655 & 0.9634 & 0.9621 & 1.0000 & 1.0000 & 1.0000 & 1.0000 & 0.7860 & 0.7876 & 0.7858 & 0.7885 \\
\hline
\end{tabular}

Appendix Table 5 The producer's risk results for Weibull distribution with supplier $\mathrm{k}=5$.

\begin{tabular}{|c|c|c|c|c|c|c|c|c|c|c|c|c|}
\hline \multicolumn{5}{|c|}{$\begin{array}{c}C_{p l, 1}=C_{p l, 2}=\ldots=C_{p l, 5}=1.00 \\
\quad(P N C=1349.89 \mathrm{ppm})\end{array}$} & \multicolumn{4}{|c|}{$\begin{array}{c}C_{p l, 1}=C_{p l, 2}=\ldots=C_{p l, 5}=1.50 \\
(P N C=3.398 \mathrm{ppm})\end{array}$} & \multicolumn{4}{|c|}{$\begin{array}{c}C_{p l, 1}=C_{p l, 2}=\ldots=C_{p l, 5}=2.00 \\
(P N C=0.001 \mathrm{ppm})\end{array}$} \\
\hline $\begin{array}{c}\text { Sample } \\
\text { Size }\end{array}$ & $\mathrm{W}(\mathbf{1}, \mathbf{1 . 0})$ & $\mathrm{W}(\mathbf{1}, \mathbf{1 . 5})$ & $\mathrm{W}(\mathbf{1}, \mathbf{3 . 6})$ & $\mathrm{W}(\mathbf{1}, \mathbf{8 . 0})$ & $\mathrm{W}(\mathbf{1}, \mathbf{1 . 0})$ & $\mathrm{W}(\mathbf{1}, \mathbf{1 . 5})$ & $W(1,3.6)$ & $\mathrm{W}(\mathbf{1}, \mathbf{8 . 0})$ & $\mathrm{W}(\mathbf{1}, \mathbf{1 . 0})$ & $\mathrm{W}(\mathbf{1}, \mathbf{1 . 5})$ & $\mathrm{W}(1,3.6)$ & $\mathrm{W}(\mathbf{1 , 8 . 0})$ \\
\hline $\mathrm{n}=15$ & 0.0004 & 0.0025 & 0.0354 & 0.1375 & 0.0007 & 0.0025 & 0.0341 & 0.1332 & 0.0010 & 0.0026 & 0.0343 & 0.1208 \\
\hline $\mathrm{n}=30$ & 0.0015 & 0.0026 & 0.0345 & 0.1389 & 0.0011 & 0.0037 & 0.0302 & 0.1289 & 0.0022 & 0.0022 & 0.0346 & 0.1216 \\
\hline $\mathrm{n}=50$ & 0.0024 & 0.0038 & 0.0323 & 0.1428 & 0.0019 & 0.0032 & 0.0284 & 0.1323 & 0.0018 & 0.0026 & 0.0319 & 0.1297 \\
\hline $\mathrm{n}=100$ & 0.0043 & 0.0031 & 0.0320 & 0.1456 & 0.0030 & 0.0033 & 0.0300 & 0.1374 & 0.0038 & 0.0027 & 0.0275 & 0.1226 \\
\hline $\begin{array}{c}\text { Sample } \\
\text { Size }\end{array}$ & W(10,1.0) & W(10,1.5) & $\mathrm{W}(\mathbf{1 0 , 3 . 6 )}$ & W(10,8.0) & W(10,1.0) & $\mathrm{W}(\mathbf{1 0}, \mathbf{1 . 5})$ & W(10,3.6) & W(10,8.0) & W(10,1.0) & $\mathrm{W}(\mathbf{1 0}, \mathbf{1 . 5})$ & W(10,3.6) & W(10,8.0) \\
\hline $\mathrm{n}=15$ & 0.0006 & 0.0030 & 0.0375 & 0.1321 & 0.0009 & 0.0035 & 0.0349 & 0.1239 & 0.0003 & 0.0033 & 0.0350 & 0.1229 \\
\hline $\mathrm{n}=30$ & 0.0012 & 0.0026 & 0.0289 & 0.1444 & 0.0008 & 0.0027 & 0.0337 & 0.1306 & 0.0010 & 0.0034 & 0.0318 & 0.1241 \\
\hline $\mathrm{n}=50$ & 0.0019 & 0.0029 & 0.0324 & 0.1451 & 0.0025 & 0.0040 & 0.0314 & 0.1314 & 0.0020 & 0.0029 & 0.0288 & 0.1284 \\
\hline $\mathrm{n}=100$ & 0.0038 & 0.0023 & 0.0302 & 0.1406 & 0.0032 & 0.0024 & 0.0308 & 0.1345 & 0.0037 & 0.0033 & 0.0315 & 0.1268 \\
\hline $\begin{array}{c}\text { Sample } \\
\text { Size }\end{array}$ & $\mathrm{W}(100,1.0)$ & $\mathrm{W}(\mathbf{1 0 0 , 1 . 5 )}$ & $\mathrm{W}(100,3.6)$ & $\mathrm{W}(\mathbf{1 0 0 , 8 . 0 )}$ & $\mathrm{W}(100,1.0)$ & $\mathrm{W}(\mathbf{1 0 0 , 1 . 5 )}$ & $\mathrm{W}(100,3.6)$ & $\mathrm{W}(100,8.0)$ & $\mathrm{W}(100,1.0)$ & $\mathrm{W}(100,1.5)$ & W(100,3.6) & $W(100,8.0)$ \\
\hline $\mathrm{n}=15$ & 0.0004 & 0.0030 & 0.0377 & 0.1342 & 0.0004 & 0.0025 & 0.0319 & 0.1288 & 0.0006 & 0.0030 & 0.0336 & 0.1174 \\
\hline $\mathrm{n}=30$ & 0.0015 & 0.0027 & 0.0316 & 0.1495 & 0.0012 & 0.0031 & 0.0305 & 0.1288 & 0.0013 & 0.0024 & 0.0303 & 0.1216 \\
\hline $\mathrm{n}=50$ & 0.0018 & 0.0025 & 0.0327 & 0.1452 & 0.0023 & 0.0021 & 0.0305 & 0.1274 & 0.0038 & 0.0033 & 0.0295 & 0.1265 \\
\hline $\mathrm{n}=100$ & 0.0037 & 0.0027 & 0.0304 & 0.1480 & 0.0046 & 0.0025 & 0.0307 & 0.1282 & 0.0033 & 0.0037 & 0.0326 & 0.1307 \\
\hline
\end{tabular}

Appendix Table 6 The producer's risk results for normal distribution with supplier $\mathrm{k}=5$.

\begin{tabular}{|c|c|c|c|c|c|c|c|c|c|c|c|c|}
\hline \multicolumn{5}{|c|}{$C_{p l, 1}=C_{p l, 2}=\ldots=C_{p l, 5}=1.00(P N C=1349.89 \mathrm{ppm})$} & \multicolumn{4}{|c|}{$C_{p l, 1}=C_{p l, 2}=\ldots=C_{p l, 5}=1.50(P N C=3.398 \mathrm{ppm})$} & \multicolumn{4}{|c|}{$C_{p l, 1}=C_{p l, 2}=\ldots=C_{p l, 5}=2.00(P N C=0.001 \mathrm{ppm})$} \\
\hline $\begin{array}{c}\text { Sample } \\
\text { Size }\end{array}$ & $\begin{array}{c}\mathbf{N} \\
(\mathbf{1 , 1})\end{array}$ & $\begin{array}{c}\mathrm{N} \\
(\mathbf{0 . 9 0 , 0 . 3 8 )}\end{array}$ & $\begin{array}{c}\mathrm{N} \\
(0.90,0.08)\end{array}$ & $\begin{array}{c}\mathrm{N} \\
(\mathbf{0 . 9 4 , 0 . 0 2 )}\end{array}$ & $\begin{array}{c}N \\
(1,1)\end{array}$ & $\begin{array}{c}\mathrm{N} \\
(\mathbf{0 . 9 0 , 0 . 3 8 )}\end{array}$ & $\begin{array}{c}\mathrm{N} \\
(\mathbf{0 . 9 0 , 0 . 0 8 )}\end{array}$ & $\begin{array}{c}\mathrm{N} \\
(0.94,0.02)\end{array}$ & $\begin{array}{c}\mathbf{N} \\
(\mathbf{1 , 1})\end{array}$ & $\begin{array}{c}\mathrm{N} \\
(0.90,0.38)\end{array}$ & $\begin{array}{c}\mathrm{N} \\
(0.90,0.08)\end{array}$ & $\begin{array}{c}\mathrm{N} \\
(0.94,0.02)\end{array}$ \\
\hline $\mathrm{n}=15$ & 0.0519 & 0.0506 & 0.0566 & 0.0522 & 0.0514 & 0.0523 & 0.0544 & 0.0556 & 0.0538 & 0.0563 & 0.0553 & 0.0547 \\
\hline $\mathrm{n}=30$ & 0.0505 & 0.0504 & 0.0477 & 0.0541 & 0.0535 & 0.0488 & 0.0502 & 0.0521 & 0.0552 & 0.0497 & 0.0502 & 0.0481 \\
\hline $\mathrm{n}=50$ & 0.0470 & 0.0515 & 0.0509 & 0.0486 & 0.0463 & 0.0474 & 0.0512 & 0.0516 & 0.0493 & 0.0500 & 0.0495 & 0.0535 \\
\hline $\mathrm{n}=100$ & 0.0509 & 0.0514 & 0.0509 & 0.0533 & 0.0521 & 0.0543 & 0.0493 & 0.0474 & 0.0477 & 0.0477 & 0.0503 & 0.0499 \\
\hline $\begin{array}{c}\text { Sample } \\
\text { Size }\end{array}$ & $\begin{array}{c}\mathrm{N} \\
(10,10)\end{array}$ & $\begin{array}{c}\mathrm{N} \\
(9.03,37.57)\end{array}$ & $\begin{array}{c}\mathrm{N} \\
(9.01,7.73)\end{array}$ & $\begin{array}{c}\mathrm{N} \\
(9.42,1.95)\end{array}$ & $\begin{array}{c}\mathrm{N} \\
(10,10)\end{array}$ & $\begin{array}{c}\mathrm{N} \\
(\mathbf{9 . 0 3 , 3 7 . 5 7 )}\end{array}$ & $\begin{array}{c}N \\
(9.01,7.73)\end{array}$ & $\begin{array}{c}\mathrm{N} \\
(9.42,1.95)\end{array}$ & $\begin{array}{c}N \\
(10,10)\end{array}$ & $\begin{array}{c}\mathrm{N} \\
(\mathbf{9 . 0 3 , 3 7 . 5 7 )}\end{array}$ & $\begin{array}{c}\mathrm{N} \\
(9.01,7.73)\end{array}$ & $\begin{array}{c}\mathrm{N} \\
(9.42,1.95)\end{array}$ \\
\hline $\mathrm{n}=15$ & 0.0553 & 0.0513 & 0.0509 & 0.0511 & 0.0549 & 0.0562 & 0.0483 & 0.0531 & 0.0536 & 0.0505 & 0.0523 & 0.0555 \\
\hline $\mathrm{n}=30$ & 0.0546 & 0.0503 & 0.0516 & 0.0521 & 0.0507 & 0.0550 & 0.0487 & 0.0546 & 0.0561 & 0.0497 & 0.0530 & 0.0490 \\
\hline $\mathrm{n}=50$ & 0.0527 & 0.0477 & 0.0491 & 0.0507 & 0.0535 & 0.0519 & 0.0520 & 0.0513 & 0.0473 & 0.0493 & 0.0526 & 0.0498 \\
\hline $\mathrm{n}=100$ & 0.0509 & 0.0491 & 0.0550 & 0.0469 & 0.0519 & 0.0514 & 0.0532 & 0.0538 & 0.0491 & 0.0505 & 0.0467 & 0.0537 \\
\hline $\begin{array}{c}\text { Sample } \\
\text { Size }\end{array}$ & $\begin{array}{c} \\
N \\
(100,1000)\end{array}$ & $\begin{array}{c}\mathrm{N} \\
(90.27,3756.90)\end{array}$ & $\begin{array}{c}\mathrm{N} \\
(\mathbf{9 0 . 1 1 , 7 7 2 . 9 5 )}\end{array}$ & $\begin{array}{c}\mathrm{N} \\
(94.17,195.16)\end{array}$ & $\begin{array}{c}\mathrm{N} \\
(\mathbf{1 0 0 , 1 0 0 0 )}\end{array}$ & $\begin{array}{c}\mathrm{N} \\
(90.27,3756.90)\end{array}$ & $\begin{array}{c}\mathrm{N} \\
(\mathbf{9 0 . 1 1 , 7 7 2 . 9 5 )})\end{array}$ & $\begin{array}{c}\mathrm{N} \\
(94.17,195.16)\end{array}$ & $\begin{array}{c}N \\
N \\
(100,1000)\end{array}$ & $\begin{array}{c}\mathrm{N} \\
(90.27,3756.90)\end{array}$ & $\begin{array}{c}\mathrm{N} \\
(90.11,772.95)\end{array}$ & $\begin{array}{c}\mathrm{N} \\
(94.17,195.16)\end{array}$ \\
\hline $\mathrm{n}=15$ & 0.0540 & 0.0516 & 0.0526 & 0.0509 & 0.0537 & 0.0528 & 0.0560 & 0.0538 & 0.0550 & 0.0532 & 0.0549 & 0.0539 \\
\hline $\mathrm{n}=30$ & 0.0485 & 0.0483 & 0.0533 & 0.0518 & 0.0493 & 0.0524 & 0.0519 & 0.0516 & 0.0549 & 0.0520 & 0.0511 & 0.0499 \\
\hline $\mathrm{n}=50$ & 0.0499 & 0.0552 & 0.0506 & 0.0511 & 0.0502 & 0.0491 & 0.0475 & 0.0529 & 0.0514 & 0.0533 & 0.0510 & 0.0507 \\
\hline $\mathrm{n}=100$ & 0.0503 & 0.0492 & 0.0489 & 0.0521 & 0.0523 & 0.0518 & 0.0478 & 0.0481 & 0.0504 & 0.0544 & 0.0510 & 0.0520 \\
\hline
\end{tabular}


Appendix Table 7 The power of test results for Weibull distribution with supplier $\mathrm{k}=5$.

\begin{tabular}{|c|c|c|c|c|c|c|c|c|c|c|c|c|}
\hline \multicolumn{5}{|c|}{$C_{p l, 1}=1.00$ vs. $C_{p l, 2}=\ldots=C_{p l, 5}=1.50$} & \multicolumn{4}{|c|}{$C_{p l, 1}=1.00$ vs. $C_{p l, 2}=\ldots=C_{p l, 5}=2.00$} & \multicolumn{4}{|c|}{$C_{p l, 1}=1.50$ vs. $C_{p l, 2}=\ldots=C_{p l, 5}=2.00$} \\
\hline Sample Size & $W(1,1)$ & $\mathrm{W}(\mathbf{1 , 1 . 5 )}$ & $W(1,3.6)$ & $\mathrm{W}(\mathbf{1 , 8 . 0 )}$ & $W(1,1)$ & $\mathrm{W}(\mathbf{1 , 1 . 5 )}$ & $W(1,3.6)$ & $W(\mathbf{1 , 8 . 0})$ & $W(1,1)$ & $\mathrm{W}(\mathbf{1 , 1 . 5 )}$ & $W(1,3.6)$ & $W(\mathbf{1}, \mathbf{8 . 0})$ \\
\hline $\mathrm{n}=15$ & 0.0004 & 0.0029 & 0.0604 & 0.3702 & 0.0004 & 0.0030 & 0.0723 & 0.5870 & 0.0008 & 0.0034 & 0.0354 & 0.1608 \\
\hline $\mathrm{n}=30$ & 0.0013 & 0.0027 & 0.0779 & 0.5858 & 0.0018 & 0.0038 & 0.1160 & 0.8393 & 0.0012 & 0.0028 & 0.0320 & 0.2095 \\
\hline $\mathrm{n}=50$ & 0.0026 & 0.0029 & 0.1295 & 0.7642 & 0.0019 & 0.0030 & 0.1842 & 0.9671 & 0.0021 & 0.0033 & 0.0356 & 0.2738 \\
\hline $\mathrm{n}=100$ & 0.0028 & 0.0034 & 0.2588 & 0.9622 & 0.0040 & 0.0036 & 0.3647 & 0.9993 & 0.0047 & 0.0031 & 0.0364 & 0.4150 \\
\hline Sample Size & $W(10,1.0)$ & $\mathrm{W}(\mathbf{1 0}, \mathbf{1 . 5})$ & $\mathrm{W}(\mathbf{1 0 , 3 . 6 )}$ & $\mathrm{W}(\mathbf{1 0 , 8 . 0 )}$ & $\mathrm{W}(\mathbf{1 0 , 1 . 0 )}$ & $\mathrm{W}(\mathbf{1 0 , 1 . 5 )}$ & $\mathrm{W}(\mathbf{1 0 , 3 . 6 )}$ & $W(10,8.0)$ & $W(10,1.0)$ & $W(10,1.5)$ & $W(10,3.6)$ & $W(10,8.0)$ \\
\hline $\mathrm{n}=15$ & 0.0009 & 0.0028 & 0.0559 & 0.3616 & 0.0003 & 0.0027 & 0.0684 & 0.5825 & 0.0006 & 0.0030 & 0.0353 & 0.1671 \\
\hline $\mathrm{n}=30$ & 0.0013 & 0.0030 & 0.0833 & 0.5780 & 0.0014 & 0.0025 & 0.1071 & 0.8457 & 0.0011 & 0.0032 & 0.0319 & 0.2163 \\
\hline $\mathrm{n}=50$ & 0.0028 & 0.0040 & 0.1271 & 0.7688 & 0.0019 & 0.0031 & 0.1781 & 0.9639 & 0.0020 & 0.0020 & 0.0317 & 0.2714 \\
\hline $\mathrm{n}=100$ & 0.0041 & 0.0044 & 0.2561 & 0.9612 & 0.0037 & 0.0035 & 0.3666 & 0.9994 & 0.0034 & 0.0034 & 0.0356 & 0.4193 \\
\hline Sample Size & W(100,1.0) & $W(100,1.5)$ & $\mathrm{W}(100,3.6)$ & $\mathrm{W}(\mathbf{1 0 0 , 8 . 0 )}$ & $W(100,1.0)$ & $\mathrm{W}(100,1.5)$ & $\mathrm{W}(100,3.6)$ & $\mathrm{W}(\mathbf{1 0 0 , 8 . 0 )}$ & $\mathrm{W}(\mathbf{1 0 0 , 1 . 0 )}$ & $\mathrm{W}(100,1.5)$ & $\mathrm{W}(100,3.6)$ & W(100,8.0) \\
\hline $\mathrm{n}=15$ & 0.0007 & 0.0039 & 0.0610 & 0.3597 & 0.0009 & 0.0043 & 0.0689 & 0.5950 & 0.0008 & 0.0028 & 0.0339 & 0.1589 \\
\hline $\mathrm{n}=30$ & 0.0014 & 0.0043 & 0.0860 & 0.5817 & 0.0008 & 0.0030 & 0.1087 & 0.8369 & 0.0012 & 0.0035 & 0.0362 & 0.2153 \\
\hline $\mathrm{n}=50$ & 0.0025 & 0.0030 & 0.1259 & 0.7652 & 0.0020 & 0.0046 & 0.1867 & 0.9653 & 0.0020 & 0.0025 & 0.0301 & 0.2759 \\
\hline $\mathrm{n}=100$ & 0.0036 & 0.0034 & 0.2622 & 0.9597 & 0.0038 & 0.0039 & 0.3761 & 0.9993 & 0.0039 & 0.0029 & 0.0347 & 0.4254 \\
\hline
\end{tabular}

Appendix Table 8 The power of test results for normal distribution with supplier $\mathrm{k}=5$.

\begin{tabular}{|c|c|c|c|c|c|c|c|c|c|c|c|c|}
\hline \multicolumn{5}{|c|}{$C_{p l, 1}=1.00$ vs. $C_{p l, 2}=\ldots=C_{p l, 5}=1.50$} & \multicolumn{4}{|c|}{$C_{p l, 1}=1.00$ vs. $C_{p l, 2}=\ldots=C_{p l, 5}=2.00$} & \multicolumn{4}{|c|}{$C_{p l, 1}=1.50$ vs. $C_{p l, 2}=\ldots=C_{p l, 5}=\mathbf{2 . 0 0}$} \\
\hline Sample Size & $\mathbf{N}(1,1)$ & $\mathrm{N}(\mathbf{0 . 9 0 , 0 . 3 8 )}$ & $\mathrm{N}(\mathbf{0 . 9 0 , 0 . 0 8 )}$ & $\mathrm{N}(0.94,0.02)$ & $\mathrm{N}(\mathbf{1 , 1})$ & $\mathrm{N}(\mathbf{0 . 9 0 , 0 . 3 8 )}$ & $\mathrm{N}(0.90,0.08)$ & $\mathrm{N}(0.94,0.02)$ & $N(1,1)$ & $\mathrm{N}(\mathbf{0 . 9 0 , 0 . 3 8 )}$ & $\mathrm{N}(\mathbf{0 . 9 0 , 0 . 0 8 )}$ & $\mathrm{N}(0.94,0.02)$ \\
\hline $\mathrm{n}=15$ & 0.3155 & 0.3076 & 0.3067 & 0.3143 & 0.7583 & 0.7620 & 0.7588 & 0.7595 & 0.1892 & 0.1852 & 0.1821 & 0.1806 \\
\hline $\mathrm{n}=30$ & 0.5637 & 0.5643 & 0.5731 & 0.5742 & 0.9687 & 0.9689 & 0.9693 & 0.9672 & 0.3324 & 0.3279 & 0.3245 & 0.3344 \\
\hline $\mathrm{n}=50$ & 0.8053 & 0.8068 & 0.8090 & 0.8049 & 0.9989 & 0.9983 & 0.9994 & 0.9986 & 0.5284 & 0.5188 & 0.5145 & 0.5183 \\
\hline $\mathrm{n}=100$ & 0.9821 & 0.9795 & 0.9821 & 0.9838 & 1.0000 & 1.0000 & 1.0000 & 1.0000 & 0.8315 & 0.8306 & 0.8246 & 0.8380 \\
\hline Sample Size & $\mathrm{N}(\mathbf{1 0 , 1 0 )}$ & $\mathbf{N}(9.03,37.57)$ & $\mathrm{N}(9.01,7.73)$ & $\mathrm{N}(9.42,1.95)$ & $\mathbf{N}(10,10)$ & $\mathrm{N}(\mathbf{9 . 0 3 , 3 7 . 5 7 )}$ & $\mathrm{N}(9.01,7.73)$ & $\mathrm{N}(9.42,1.95)$ & $\mathbf{N}(\mathbf{1 0 , 1 0 )}$ & $\mathrm{N}(\mathbf{9 . 0 3 , 3 7 . 5 7 )}$ & $\mathbf{N}(9.01,7.73)$ & $\mathrm{N}(\mathbf{9 . 4 2 , 1 . 9 5 )}$ \\
\hline $\mathrm{n}=15$ & 0.3087 & 0.3221 & 0.3107 & 0.3103 & 0.7628 & 0.7573 & 0.7691 & 0.7597 & 0.1770 & 0.1790 & 0.1803 & 0.1804 \\
\hline $\mathrm{n}=30$ & 0.5765 & 0.5784 & 0.5782 & 0.5716 & 0.9720 & 0.9717 & 0.9716 & 0.9711 & 0.3242 & 0.3188 & 0.3323 & 0.3322 \\
\hline $\mathrm{n}=50$ & 0.8055 & 0.8096 & 0.8035 & 0.8061 & 0.9985 & 0.9990 & 0.9987 & 0.9981 & 0.5205 & 0.5206 & 0.5238 & 0.5163 \\
\hline $\mathrm{n}=100$ & 0.9825 & 0.9848 & 0.9825 & 0.9826 & 1.0000 & 1.0000 & 1.0000 & 1.0000 & 0.8347 & 0.8254 & 0.8366 & 0.8279 \\
\hline Sample Size & $\begin{array}{c}\mathrm{N} \\
(\mathbf{1 0 0 , 1 0 0 0 )} \\
\end{array}$ & $\begin{array}{c}\mathrm{N} \\
(\mathbf{9 0 . 2 7 , 3 7 5 6 . 9 0 )} \\
\end{array}$ & $\begin{array}{c}\mathrm{N} \\
(90.11,772.95) \\
\end{array}$ & $\begin{array}{c}\mathrm{N} \\
(94.17,195.16) \\
\end{array}$ & $\begin{array}{c}\mathrm{N} \\
(\mathbf{1 0 0 , 1 0 0 0 )} \\
\end{array}$ & $\begin{array}{c}\mathrm{N} \\
(\mathbf{9 0 . 2 7 , 3 7 5 6 . 9 0 )} \\
\end{array}$ & $\begin{array}{c}\mathrm{N} \\
(\mathbf{9 0 . 1 1 , 7 7 2 . 9 5 )} \\
\end{array}$ & $\begin{array}{c}\mathrm{N} \\
(94.17,195.16) \\
\end{array}$ & $\begin{array}{c}\mathrm{N} \\
(\mathbf{1 0 0 , 1 0 0 0 )} \\
\end{array}$ & $\begin{array}{c}\mathrm{N} \\
(90.27,3756.90) \\
\end{array}$ & $\begin{array}{c}\mathrm{N} \\
(\mathbf{9 0 . 1 1 , 7 7 2 . 9 5 )} \\
\end{array}$ & $\begin{array}{c}\mathrm{N} \\
(94.17,195.16) \\
\end{array}$ \\
\hline $\mathrm{n}=15$ & 0.3148 & 0.3108 & 0.3091 & 0.3126 & 0.9681 & 0.7614 & 0.7646 & 0.7688 & 0.1797 & 0.1784 & 0.1744 & 0.1847 \\
\hline $\mathrm{n}=30$ & 0.5647 & 0.5780 & 0.5760 & 0.5755 & 0.9985 & 0.9680 & 0.9689 & 0.9692 & 0.3261 & 0.3329 & 0.3276 & 0.3299 \\
\hline $\mathrm{n}=50$ & 0.8089 & 0.8083 & 0.8064 & 0.8095 & 1.0000 & 0.9980 & 0.9991 & 0.9991 & 0.5192 & 0.5207 & 0.5181 & 0.5205 \\
\hline $\mathrm{n}=100$ & 0.9833 & 0.9823 & 0.9845 & 0.9819 & 1.0000 & 1.0000 & 1.0000 & 1.0000 & 0.8293 & 0.8307 & 0.8275 & 0.8323 \\
\hline
\end{tabular}

